\title{
НЕКОТОРЫЕ АСПЕКТЫ КЛАСТЕРНОГО ПОДХОДА К ПОВЫШЕНИЮ ЭНЕРГОЭФФЕКТИВНОСТИ ЭЛЕКТРОГЕНЕРИРУЮЩИХ ПРОИЗВОДСТВ
}

\author{
(C) 2013 г. С. А. Москаленко
}

\section{Новочеркасская государственная мелиоративная академия}

Рассматривается конщепция кластерного подхода к развитию электрогенерирующего производства на базе крупных электростаниий (ТЭС, ГЭС). Дается характеристика современной тенденции развития кластерной организации экономики на основе концепции формирования территориально-производственных комплексов, как одной из форм повьшения конкурентоспособности отдельных отраслей и производств. Рассматривается стратегия формирования региональных кластеров на базе крупной электростанщии и агропромышленного комплекса региона, включая совместную кооперацию по развитию инфраструктуры, совместных производств, утилизаиии отходов, производству удобрений и химических реагентов, развитию перерабатывающих отраслей, расширению рынка сбыта электроэнергии и продуктов переработки. Рассмотрена стратегия государственной поддержки указанного направления и «дорожная карта» на период до 2030 г.

Ключевые слова: электрогенерирующее производство; электростанция; агропромышленный комплекс; энергоагропромышленный кластер; диверсификация; кооперация; межотраслевые экономические отношения; дорожная карта.

The concept of the cluster approach to the development of power generation on the basis of the production of large power plants (TPP, HPP) is examined in the article. A characteristic of the modern trends in the cluster of economic organization based on the concept of clusters' formation as a form of improving the competitiveness of individual sectors and industries is given. Considered a strategy of creating the regional clusters, based on large power plants and agriculture in the region, including joint cooperation on infrastructure development, joint production, waste management, fertilizer and chemicals, the development of processing industries, the expansion of market power and by-products. Author also considered the strategy of state support specified direction and the «road map» for the period up to 2030.

Key words: electricity production; power; agriculture; electricity production and agriculture cluster; diversity; cooperation; economic relations between the branches; a road map.

В ближайшие десятилетия мировые экономики (по крайней мере, экономики ведущих стран - США, Германия, Китай и Россия) в силу объективных причин перейдут на угольные (сланцевые) технологии энергетики, поэтому необходима их адаптация к требованиям, во-первых, экологической безопасности населения и биосферы, во-вторых, эффективности и конкурентоспособности с другими технологиями энергопроизводства.
Здесь важна, не столько экономическая эффективность энергопроизводства и комплекса связанных с ним инновационных технологий комплексного использования топлива, сколько дополнительно созданная добавленная стоимость от второго и последующих переделов топлива, синергетический эффект за счет комплексного использования вторичных относительно топлива ресурсов (тепловая энергия, газовоздушные выбросы и твер- 
дые отходы, использование потенциальной энергии водных потоков охлаждения и т. п.).

В контексте Закона РФ об энергоэффективности (2009 г.) энергоэффективность ТЭС и других энергопроизводящих предприятий нами трактуется как величина основной и дополнительной создаваемой добавленной (прибавочной) стоимости на 1 кВт установленной мощности (или 1 т использованного топлива) от реализации основной товарной продукции (электроэнергия) и товарной продукции и услуг, получаемых в результате последующих переделов как топливного ресурса, так и получения дополнительной сопутствующей товарной продукции за счет утилизации промышленных отходов, низкопотенциальных тепла и гидроресурсов, эффективного использования электроэнергии самой электростанцией, в том числе полученной дополнительно за счет энергосбережения.

Например, получение и реализация на базе ТЭС, ГРЭС и других электростанций дополнительной товарной продукции или услуг как результат диверсификации их деятельности позволит получить дополнительно до 5-10\% добавленной стоимости на 1 кВТ установленной мощности, что повысит их энергоэффективность и создаст региональный центр локализации принципа «опоры на собственные силы» в региональных экономических системах.

Повышение экономической эффективности использования природных ресурсов, рационального их использования и снижение негативного воздействия на окружающую среду и человека возможно при комплексном подходе к использованию ресурсов, и соответственно комплексного экономического развития территорий. Таким образом, важным принципом локализации размещения производства следует считать комплексное использование природных ресурсов, включая энергетические, и «отходы» их использования. Критерий эффективности такого размещения и организации - увеличение добавленной стоимости, повышение дохода на единицу использованного ресурса, включая эффекты коммерциализации мероприятий охраны окружающей среды.

Производственный комплекс в таком случае возникает на основе его ориентации на определенный вид природного ресурса, например, топлива (уголь, газ, ядерное топливо, потенциальная энергия воды и др.) энергопроизводящих предприятий. Здесь завершенность, замкнутость технологических процессов есть предпосылка организации малоотходного производства. В нашем случае производственная кооперация и комбинирование выводятся из устойчивого сочетания технологических процессов, по своей сути - энергопроизводственных циклов Н. Н. Колосовского.

Здесь следует отметить важное обстоятельство - увеличение общего эффекта в связной и структурированной экономической системе значительно больше, чем простая сумма эффектов её субъектов, действующих независимо (синергетический эффект). Данное обстоятельство должно стать побудительным мотивом, как для субъектов системы, так и органов государственного управления для их интеграции в рамках региональных экономических кластеров. Такое объединение будет сохранять свою жизнеспособность до тех пор, пока его функционирование будет отвечать критериям устойчивости экономических систем - критериям эффективности (экономическим, экологическим, социальным), определяющим жизнеспособность и конкурентоспособность системы как внутри её границ, так и жизнеспособность системы в изменяющейся внешней конкурентной экономической среде.

В последние годы новые технологии «проникают» во все сектора экономики и социальные сферы. Проведенные прогнозные исследования позволяют оценить возможные направления глобального развития, наметить горизонты отдельных научно-технологических областей и определить в них перспективные инновации, ожидаемые технические, технологические, экономические, экологические и социальные эффекты, которые могут быть получены в результате их реализации. Так, корпорация RAND выделяет более 50 технологий [1], которые будут способствовать развитию целых отраслей, окажут наиболее глубокое и многостороннее влияние на экономику и общество, по крайней мере, в течение ближайшего десятилетия, и приложения которых сформируют новые рынки. Среди таких технологий применительно к 
нашим исследованиям выделим: технологии использования возобновляемых источников энергии, системы и технологии для очистки и обеззараживания воды, экологически чистые и малоотходные технологии, нетрадиционные виды топлива, в частности, водородное топливо.

Полагаем, что движение по базовому, энергосырьевому (инерционному) сценарию в масштабе РФ в целом, и для Ростовской области, в частности, в складывающейся после вступления России в ВТО геоэкономической и геополитической ситуации будет означать фактическую стагнацию ещё существующего индустриального комплекса. Для промышленности Ростовской области это, фактически инерционно-стагнационный сценарий, консервирующий компрадорскую модель региональной экономики. Предпочтительным в этой связи может быть альтернативный сценарий, в котором должна четко просматриваться инновационная составляющая. Реализации такого мобилизационноинновационного сценария для Ростовской области, ориентированного на собственные силы, должна способствовать структурная специфика региональной экономики - наличие как ресурсов для создания собственной продовольственной базы, так и топливно-энергетических ресурсов, и достаточно диверсифицированная промышленность. В контексте развития ТЭК региона усилия должны сосредотачиваться на следующих основных направлениях:

- создание на базе промышленных предприятий области производств, ориентированных на выпуск агрегатов электрической генерации (ветровые и гидросиловые установки), систем очистки и обеззараживания воды;

- развитие на территории области высокотехнологичных и экологичных энергопроизводственных циклов на базе угольных месторождений Восточного Донбасса, ветровых и гидроресурсов региона, возврата местного угля в тепловую электроэнергетику;

- технико-технологическая модернизация, диверсифицирующая энергопроизводящие предприятия области в целях существенного повышения их энергоэффективности и, тем самым, роста конкурентоспособности региона на российском, а после вступления в ВТО - на мировом рынке.
В рамках указанных направлений имеется возможность как снижения базовых издержек, так и повышения энергоэффективности в рамках формирования «замкнутых», базирующихся преимущественно на собственном энергетическом потенциале, региональных экономических кластеров. Указанные действия позволят создать в рамках кластеров диверсифицированные конкурентоспособные энергопромышленные производства, увеличить глубину переработки топлива, повысить энергоэффективность производства и его экологичность, расширить присутствие на рынках товаров на базе последовательных переделов (после первого передела - получения электроэнергии) сырья и топлива, выйти на рынки с более широким спектром конкурентоспособной продукции с более высокой долей добавленной стоимости.

Это позволит скорректировать общую функциональность региона, а также встроить в модель региональной экономики такую доминанту как «экологического сервис» применительно к аграрной экономике (органические удобрения, сернокислотный мелиорант и др.), жилищно-коммунальному хозяйству (гипохлорит натрия, пероксид водорода), другим сферам деятельности, превратить регион в ведущую площадку инновационной реиндустриализации Юга России.

Содержательная сторона идеи кластеризации применялась в СССР в виде «межотраслевых и территориальных комплексов», структура, содержание и терминология которых была определена известными отечественными учёными - Н. Н. Колосовским, Г. М. Кржижановским, В. С. Немчиновым. Так, Н. Н. Колосовский определил производственный комплекс как системность территориальной организации экономики и комплексное использование естественных и общественных ресурсов района.

В 1993 году М. Портер дал общее определение кластера (от англ. cluster - концентрация, скопление) применительно к экономике в целом: «кластер - группа географически соседствующих взаимосвязанных компаний и связанных с ними организаций, действующих в определённой сфере и взаимодополняющих друг друга» [2, с. 68]. Изучению вопросов кластеризации посвящены работы ряда российских экономистов: С. Г. Важенина, 
С. В. Валдайцева, А. Г. Гранберга, С. В. Лозинского и других.

Для описания географических скоплений отраслей, предприятий и связанных с ними процессов, кроме термина «кластер» используются и другие понятия, определяющие иные подобные организационные структуры: индустриальные районы, территориальнопроизводственные комплексы, региональная инвестиционная среда.

Кластер и вышеуказанные иные организационные структуры имеют как общие кооперация, концентрация, территориальная локализация, межотраслевое взаимодействие, особенности инфраструктуры, так и отличительные черты, присущие кластеру - внутренняя конкуренция, ориентированность на рынок, гибкость, научный потенциал. Кроме того, следует отметить важные черты, которые должны быть присущи кластеру: во-первых, возникновение синергетического эффекта, во-вторых, объединение предприятий или производств (производственных процессов) в единый кластер производится по их участию в цепочке добавленной стоимости.

Основной задачей кластеров является снижение уровня неопределённости в экономических процессах за счёт создания устойчивых структур взаимодействия между предприятиями и организациями, поддержания обмена инновациями и ресурсами между предприятиями, защиты групповых интересов и снижения транзакционных издержек. При этом экономические кластеры имеют два доминирующих типа взаимосвязей: первый - выражает отношения «покупательпродавец», т. е. вертикальные, второй - горизонтальные связи предприятий разных отраслей, которые работают на общем рынке конечных продуктов, используют общую системообразующую технологию или их цепочки, сходные природные ресурсы (сырьё) или «производимые» из них отходы. Экономические кластеры могут создаваться по инициативе органов государственного управления или по инициативе самих участников кластера при наличии благоприятных условий в регионе, либо при взаимодействии государства с участниками кластера. Ряд экономистов считает, что кластерный подход к организации экономики оказывает положи- тельное влияние на её состояние.

В последние два десятилетия в аспекте регионального развития наметилась тенденция формирования так называемых производственно-экономических кластеров, которые, являясь, по сути, межотраслевыми комплексами, играют роль «точек роста» региональной и национальной экономики в целом [3-5]. При этом кластеры позволяют преодолеть структурные ограничения, а также сложившуюся в ряде хозяйствующих субъектов многоотраслевую структуру производства.

В данном контексте кластер представляет собой группу географически локализованных взаимосвязанных компаний, поставщиков сырья и энергоносителей, оборудования, комплектующих, специализированных услуг, инфраструктуры и других организаций, взаимодополняющих друг друга и усиливающих конкурентные преимущества как отдельных компаний так и кластера в целом. Взаимодействие предприятий и организаций, входящих в кластер, осуществляется на принципах кооперации и конкуренции, т. е. происходит постоянный обмен кадрами, инновациями, технологиями, осуществляется совместное использование инфраструктуры, услуг и рекламно-маркетинговое продвижение. Постоянное взаимодействие, обмен ресурсами и информацией внутри кластера приводят к принятию и использованию внутренних систем ограничений, которые выражаются в стандартах и типовых процедурах управления. Такое понимание содержания кластера подтверждает тезис о том, что первичные факторы в развитии бизнеса - уровень используемых технологий и качество управления.

Рассмотрим специфический региональный кластер на базе электрогенерирующего производства (крупной электростанции), который может являться ядром и структуроформирующим фактором для отдельных секторов региональной экономики. Одной из форм повышения конкурентоспособности электрогенерирующего производства на основе кооперации со смежными объектами производственными предприятиями региона, в частности - для Юга России, это объекты агропромышленного комплекса, зависящие в существенной мере от энергопоставок, но могут быть заинтересованы и в других побоч- 
ных продуктах и ресурсах электростанций, поставка которых в кооперации с энергопроизводящими предприятиями может быть взаимовыгодной - можно считать реализацию кластерного подхода в форме энергоагропромышленного кластера.

Экономические энергоагропромышленные кластеры, в данном контексте, являются инструментом активной экономической политики, обеспечивающей конкурентоспособность экономики региона в условиях открытого рынка.

Заинтересованность электроэнергетики в развитии подобной кооперации следует из целевых ориентиров «Энергетической стратегии России на период до 2030 года», основные положения которой сводятся к следующему $[6 ; 7]$ : ВВП;

- снижение удельной энергоемкости

- снижение удельных потерь;

- повышение эффективности действующих технологий;

- развитие экологически чистых производств.

Указанные направления формируются общемировыми тенденциями в развитии энергетики и энергосбережения в современных условиях, а именно: ВВП;

- неуклонное снижение энергоемкости

- снижение конкурентоспособности традиционной энергетики;

- развитие и повышение конкурентоспособности альтернативных энергоисточников;

- усиление экологических требований;

- повышение энергоэффективности энергетики в целом.

Моделирование направлений и процедур повышения технологической, эколого-экономической и коммерческой эффективности деятельности крупных сетевых электростанций (ГЭС, ТЭС) предполагает учёт следующих факторов:

- установление межотраслевых экономических отношений крупного объекта электрогенерации со смежными отраслями экономики;

- развитие интеграции и кооперации в сфере основного производства и утилизации отходов;
- создание региональных производственно-экономических, включая и энергоагропромышленные, кластеров.

Продукция электростанций - электроэнергия, как известно, не относится к товару с высокой степенью передела сырья и потому не обладает высокой добавленной стоимостью. Причём основная часть добавленной стоимости энергопроизводства, значительной доли энергетической составляющей валового регионального продукта (ВРП), и ВВП страны в целом, остается сетевым и распределительным компаниям. Следствием этого являются и повышенные тарифы для конечного потребителя, и проблема стоимостной компенсации потерь в сетях. В результате основная доля добавленной стоимости и прибыли «уводится» от объекта электрогенерации к сетевым и распределительным компаниям. При этом крупный объект электрогенерации «производит» значительный побочный продукт (избыточное тепло, твёрдые и газообразные отходы и др.), который может быть непосредственно предложен потребителям, либо утилизирован с дополнительной прибылью для генерирующей компании. Вполне очевидно, что дополнительный эффект электрогенерирующего объекта должен проявляться в товарной сопряженности энергетики со смежными отраслями.

Возможное направление диверсификации объекта электрогенерации может быть сформулировано в рамках кластерного подхода. В этом случае крупная электростанция (ТЭС, ГЭС) рассматривается как ядро регионального энергоагропромышленного комплекса (кластера). Ожидаемый результат заключается в следующем:

- синергетический эффект, как результат, интеграционно-кооперативного развития региональной экономики на принципах диверсификации деятельности крупных энергопроизводящих предприятий с целью повышения энергоэффективности самой генерации и развития смежных с ней производств;

- расширение рынка сбыта излишков тепловой энергии по выгодным тарифам;

- получение дополнительного дохода от утилизации отходов собственного производства и произведённой на их базе товарной продукции.

Формирование энергоагропромышлен- 
ного кластера осуществляется на основе объединения (создание холдинга, консорциума и др.) заинтересованных контрагентов, ядром которого является энергопроизводящий объект.

Условия для формирования кластера это экономическое (взаимообусловленное) сочетание на принципах функционирования экологических систем предприятий в близлежащем географическом контуре с генерирующим объектом, при кооперации с которыми достигается существенный экономический и экологический эффекты. При этом должны учитываться:

- природные и экономические условия региона;

- транспортная и производственная инфраструктура;

- экономико-географическое положение;

— природно-ресурсный потенциал региона.

Производственная кооперация в формируемом кластере осуществляется через комбинирование устойчивых сочетаний энергопроизводственных процессов (на ТЭС, ГЭС) и взаимообусловленного производства дополнительной товарной продукции на основе электроэнергии, сырья (вода, химические реагенты и др.), отходящих газов $\left(\mathrm{SO}_{2}, \mathrm{NO}_{\mathrm{x}}\right)$ отводимого тепла и других побочных продуктов (отходов) процесса электрогенерации.

Направления кооперации:

- прямые поставки электроэнергии потребителям внутри кластера;

- производство азотных удобрений;

- производство сернокислотного мелиоранта;

- производство гипохлорита натрия и других химических реагентов;

- организация тепличных хозяйств на базе использования избыточной тепловой энергии;

- организация сети крупных холодильников на низкопотенциальной энергии в трубопроводах высокого давления;

- переработка отходов производства;

- возобновляемые источники энергии (на вспомогательных гидротехнических сооружениях, отходах производства, низкопотенциальных источниках энергии) для обеспечения собственных нужд.
Структурная схема энергоагропромышленного кластера на базе крупного объекта электрогенерации представлена на рис. 1 и предполагает кооперацию со следующими секторами региональной экономики: АПК, ЖКХ, городское хозяйство, предприятия стройиндустрии и другие сферы обеспечения жизнедеятельности потребителей экологических услуг.

По предварительным оценкам результат подобной кооперации обеспечит получение дополнительного дохода внутри кластера от 5\% до $40 \%$ добавленной стоимости в зависимости от глубины и широты развития кооперативных отношений, что естественно повысит энергоэффективность энергопроизводящего объекта.

Выделим следующие источники дополнительного дохода:

- уменьшение производственных потерь сырья и энергии;

- перераспределение между объектом генерации и потребителями части добавочной стоимости сетевых компаний;

- производство дополнительной товарной продукции за счёт рационального использования сырья и энергии: минеральные удобрения, гипохлорит натрия, пероксид водорода, сернокислотный мелиорант, сельскохозяйственная продукция тепличных хозяйств, услуги холодильников, материалы стройиндустрии и пр.;

- сокращение платежей за загрязнение окружающей среды.

Рассмотрим некоторые аспекты, определяющие перспективность развития данного направления в соответствии с существующими тенденциями в определенной структурной и временной развертке:

1. Определим заинтересованных участников, экономических агентов и контрагентов:

- генерирующие компании (РусГидро, ОГК, ТПС и др.);

- крупные объекты электрогенерации (ГРЭС, ТЭС, ГЭС) - ядро кластера;

- крупные сельскохозяйственные производители (в перспективе - мегааграрные системы, по А. И. Липковичу) - в основе их формирования и развития может лежать кооперация с энергопроизводящим объектом;

- совместные предприятия по производ- 


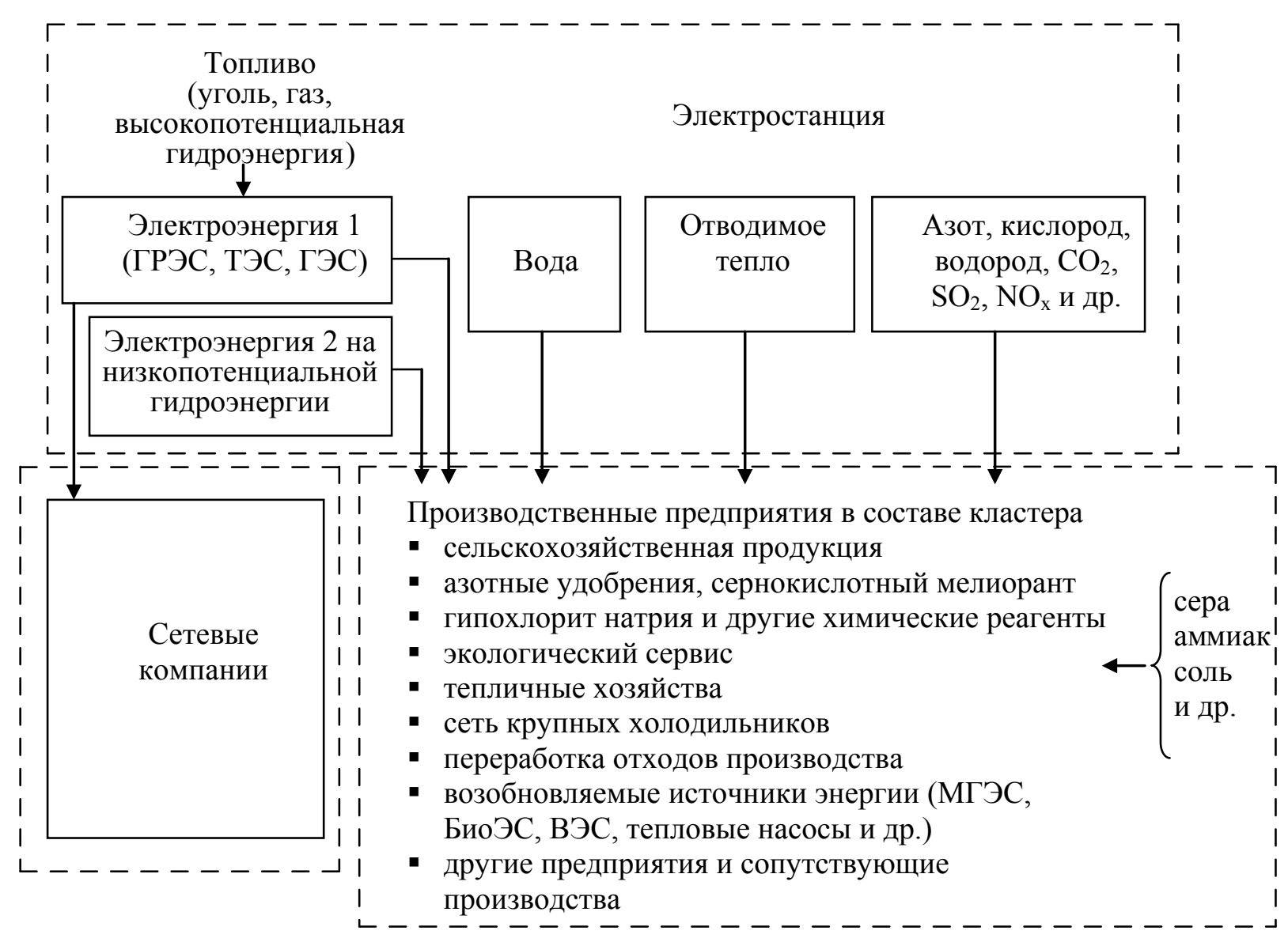

Рис. 1. Структурная схема энергоагропромышленного кластера

ству удобрений и химреагентов, отраслевые производства, переработка и реализация продукции, тепличные хозяйства, утилизация отходов производства и потребления, предприятия водоснабжения;

- инфраструктурные звенья (подстанции, ЛЭП, участки автомобильных и железных дорог, трубопроводы и т. д.);

- проектные, инжиниринговые, консалтинговые, экспертные компании;

- региональные и федеральные госструктуры и ведомства.

2. Возможные сценарии экоразвития в контексте кластерного подхода:

- импульс развитию сельского хозяйства региона и его инновационное возрождение;

- развитие индустрии местных удобрений и мелиорантов по доступным ценам;

- решение проблемы экологически безопасной питьевой воды, прежде всего, для сельского населения региона;

- конкурентоспособность и экологически устойчивое развитие региональной экономики;

- консолидация государственного и частного сектора;

- улучшение экологической обстановки в регионе;

- усиление социального фактора (дополнительные рабочие места, комфортность проживания в сельской местности);

- улучшение социально-психологического климата в регионе.

Важное условия для успешного развития рассматриваемого направления - наличие государственной поддержки. Она может быть реализована в различных формах и направлениях:

— частно-государственное партнерство;

- региональные социально-предпри- 
нимательские корпорации под патронажем государственных структур (по опыту Казахстана);

- формирование благоприятной экономической и правовой среды через законодательные и организационные механизмы (институциональный фактор);

- создание инвестиционной привлекательности региона;

— толерантная к бизнесу фискальная политика;

- целевые региональные инвестиционные программы.

3. Дорожная карта на период 20132030 гг.

a) мероприятия на период 2013-2015 г2.:

- разработка стратегических планов в терминах программно-целевого планирования, включающих инвестиционные проекты для отдельно выбранных пилотных объектов и регионов;

- разработка пилотных инвестиционных проектов будущих энергоагропромышленных кластеров для отдельных крупных объектов электрогенерации (ГРЭС, ТЭС, ГЭС) и перспективных производств на выделенных территориях;

- осуществление необходимых законодательных инициатив.

б) мероприятия на период 2016-2020 г2.:

- формирование частно-государственного партнерства, региональной социальнопредпринимательской корпорации;

- формирование организационных структур и экономических механизмов поддержки энергопроизводственных кластеров;

- выбор источников инвестиций и создание необходимых инвестиционных механизмов (финансовых инструментов);

- реализация пилотных региональных проектов.

в) мероприятия на период 2021-2030 г2.:

- накопление опыта, совершенствование разработанных механизмов, подготовка условий для реализации аналогичных проектов в других регионах;

- реализация аналогичных проектов для других объектов и регионов;

- укрупнение действующих кластеров, совершенствование инновационных технологий.
Таким образом, направление повышения эффективности функционирования крупных сетевых электростанций, в контексте кластерных подходов, может рассматриваться как один из возможных сценариев развития так называемой «умной генерации» будущего и, одновременно как фактор устойчивого развития региональной экономики на базе кластерной организации.

\section{Литература}

1. Silberglitt R., Anton P., Howell D., Wong $A$. The Global Technology Revolution 2020: InDepth Analysis: RAND Technical Report. Santa Monica; Arlington; Pittsburg, 2006.

2. Портер М. Конкуренция. - М.: Издательский дом «Вильямс», 2005. - 608 с.

3. Пилипенко И. В. Кластеры и территориально-производственные комплексы в региональном развитии. // Региональное развитие и региональная политика России в переходный период. / Под общ. ред. С. С. Артоболевского, О. Б. Глезер. - М.: МГТУ им. Н. Э. Баумана, 2011. - С. 191-208.

4. Кравиов Ю. А. Региональная инноватика модернизации. // Экономика и бизнес. - 2010. - №3. - С. 15-18.

5. Лазарева Е. И. Кластерная политика эффективной интеграции региона в процесс качественного экономического роста. // Экономический вестник Ростовского государственного университета. - 2006. - №3. - С. 283.

6. Концепция долгосрочного социально-экономического развития Российской Федерации на период до 2020 года: Распоряжение Правительства Российской Федерации от 17 ноября 2008 г. №1662-р [Электронный ресурс] / Информационно-правовой портал «Гарант». - Режим доступа: http://www. garant.ru/products/ipo/prime/doc, свободный. - Загл. с экрана.

7. Энергетическая стратегия России на период до 2030 года: Распоряжение Правительства Российской Федерации от 13 ноября 2009 г. №1715-р [Электронный ресурс] / Информационно-правовой портал «Гарант». Режим доступа: http://www.garant.ru/products/ ipo/prime/doc, свободный. - Загл. с экрана. 


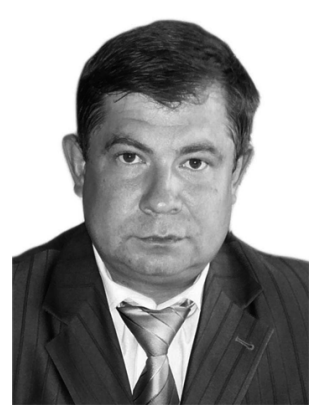

Станислав Александрович Москаленко - кандидат экономических наук, доцент кафедры экономики Новочеркасской Государственной мелиоративной академии.

Stanislav Aleksandrovich Moskalenko - Ph.D., Candidate of Economics, docent at the Economics department of the Novocherkassk State Academy of Land Reclamation.

346410, Ростовская обл., г. Новочеркасск, ул. Фрунзе, д. 37

37 Frunze st., 346410, Novocherkassk, Rostov reg., Russia

Тел.: +7 (928) 15-21-814; e-mail: stanislav-moskalenko@yandex.ru

\title{
МИНИСТЕРСТВО ОБРАЗОВАНИЯ И НАУКИ РОССИЙСКОЙ ФЕДЕРАЦИИ ТОЛЬЯТТИНСКИЙ ГОСУДАРСТВЕННЫЙ УНИВЕРСИТЕТ
}

\author{
при поддержке Российского гуманитарного научного фонда \\ (проект РГНФ 13-03-14040)
}

\section{6-27 сентября 2013 г.}

проводят

Всероссийскую научно-практическую конференцию

«Инновационная активность современных российских промышленных предприятий: междисциплинарные научные подходы, результаты исследований, опыт социальных преобразований»

Цель конференции - интеграция научных исследований по проблемам интенсификации развития современных российских промышленных предприятий на основе инновационной активности.

К участию в конференции приглашаются все заинтересованные в развитии и исследовании внедрения инноваций: инженерно-технические специалисты, специалисты в сфере экономики, управления, права, исследования социальных процессов руководители, преподаватели вузов, аспиранты, молодые специалисты, студенты.

Для участия в конференции необходимо до 1 июля 2013 г. выслать статью и регистрационную форму по электронной почте sci-res@yandex.ru. Материалы представляются только в электронном виде.

Организатор: Тольяттинский государственный университет Контактный телефон: +7 (903) 330-20-43 